\title{
The use of data-driven technologies in tourism marketing
}

\section{By Mark Anthony Camilleri, University of Malta ${ }^{1}$, MALTA and University of Edinburgh ${ }^{2}$, SCOTLAND.}

This is a pre-publication version.

How to Cite: Camilleri, M.A. (2019). The Use of Data Driven Technologies in Tourism Marketing. In Ratten, V., Alvarez-Garcia, J. and De 1 Cruz Del Rio-Rama, M., Entrepreneurship, Innovation and Inequality: Exploring Territorial Dynamics and Development, 1st Edition, Routledge, Oxford, UK.

https://www.routledge.com/Entrepreneurship-Innovation-and-Inequality-ExploringTerritorial-Dynamics/Ratten-Alvarez-Garcia-Rio-Rama/p/book/9780367263218

Keywords: Tourism, Tourism Technologies, eTourism, Digital Media, Analytics, Big Data, Blockchain, Programmatic Advertising, Digital Marketing.

\section{Introduction}

The ongoing advances in technology have brought significant improvements in the processing speed and storage of large volumes of data. Tech-savvy organisations have already started using big data with a goal to improve their decision making, agility and customer-centric approaches. Today, many tourism marketers are hyper-targeting consumers with real-time mobile ad campaigns to drive conversions. They use analytics to identify how exogenous variables, including the broader economy, competitive offerings and even the weather can affect their organisational performance (Nichols, 2013). Similarly, the smaller enterprises are economically gathering and storing data from each and every customer transaction. They use analytics to customise their offerings and improve their customer engagement (Ransbotham and Kiron, 2018).

\footnotetext{
${ }^{1}$ Department of Corporate Communication, Faculty of Media and Knowledge Sciences, University of Malta, Msida, MSD2080, MALTA. Email: mark.a.camilleri@um.edu.mt

${ }^{2}$ The Business School, University of Edinburgh, 29 Bucchleuch Place, Edinburgh, EH8 9JS, SCOTLAND.
} 
Therefore, this chapter builds on the previous theoretical underpinnings on smart tourism (Camilleri, 2018, 2017; Buhalis and Amaranggana, 2013; Gretzel et al., 2015; Li et al., 2017; Wang et al., 2013). It clarifies how smart, disruptive technologies have led to endless opportunities for tourism and hospitality marketers to gain a competitive advantage. It explains how they are leveraging themselves by utilising contemporary marketing strategies and tactics that are customer-focused. The researcher examines the use of big data, analytics, programmatic advertising and blockchain technologies in the realms of tourism and hospitality.

\section{The uses of big data and analytics}

For decades, organisations have been gathering and analysing digital data in some way or another to improve their performance. The new advantages of crunching big data analytics are based on the discovery of how to improve productivity levels and agility to enhance the businesses' financial performance (Chen and Zhang, 2014; Wang et al., 2018). The latest technological advances have enabled many tourism businesses, including airlines and hotels to manage their operations in a more efficient and economical way (Camilleri, 2017; Liu et al., 2017; Pan and Yang, 2017). Several airlines and hotels are increasingly using revenue management systems that are quickly adjusting offers (Pan and Yang, 2017). The pricing of their products is usually based on

a variety of situations and circumstances, as they optimise communications and transactions. By using data and analytics on the customers' behaviours, many travel businesses are taking advantage of channel-based distribution. Hence, the distribution networks have come a long way from the ticket counter. Evidently, travel and tourism businesses are leveraging themselves with data-driven marketing, as they seek new customers and prospects (Camilleri, 2017). For instance, they may increase their profitability from high-yield customers through elaborated pricing and revenue management systems. Hence, the travel distribution is evolving from its current passive, rigid and technology-centric state to a more flexible, dynamic and passenger-centric environment as airlines and hotels monitor and detect any changes in their consumers' behaviours. 
The terms of "big data" and "analytics" are increasingly being used to describe data sets and analytical techniques in applications ranging from sensors to social media that require advanced and unique storage, management, analysis and visualisation technologies (Boyd and Crawford, 2012; Chen et al., 2012). There are a number of concepts, including volume, variety, velocity, veracity and value that are associated with big data. Usually, big data analytics are dependent on an extensive storage capacity and processing power, requiring a flexible grid that can be reconfigured for different needs (Stergiou et al., 2018). Information technology (IT) systems may reveal valuable insights on the businesses' customers. They can indicate which products or services are sought by customers. For instance, they may reveal where and what customers eat, where and when they go on vacation, how many products they buy, etc.

The explosion of online and mobile activity from e-commerce and social media has led to the dissemination of meaningful data that is being created online ( $\mathrm{Li}$ et al., 2017; Sigala, 2017). Big data environments ought to make sense of the content they gather. This means that IT applications need to scrutinise and report on a wide variety of dimensions including customer interactions, product usage, service actions and other dynamic measures. Such content may include text messages, document images, pictures, video clips, web logs, etc.

\section{Capturing data}

The business environment is currently witnessing a sea of change in IT activity. The expansion of big data use has been generated by the web and its online communities. E-commerce vendors including Amazon and eBay have surely transformed the market through their innovative and highly scalable e-commerce platforms and product recommender systems. Moreover, internet giants like Google and Facebook are leading the development of web analytics, cloud computing and social media platforms (Ratten, 2020). The emergence of user-generated content on fora, newsgroups, social media networks and crowd-sourcing platforms has offered endless opportunities for researchers and practitioners to "listen" to marketplace stakeholders including customers, employees, investors and the media (Abbasi et al., 2016; Sigala, 2017). As 
a result, businesses are increasingly collecting and analysing data from various sources to improve their customer-centric marketing.

The online review sites and personal blogs may provide opinion-rich information that may be explored through textual and sentiment analysis (Cambria, 2016; Gao et al., 2018; Xiang et al., 2017). Social media analytics are increasingly capturing fastbreaking trends on customer sentiments about products, brands and companies. Businesses may be interested in knowing whether there are changes in online sentiment and how these may correlate with changes in sales, or in consumer tastes, over time. In big data environments it's important to analyse, decide and act expeditiously. Businesses should be quick in their decision making and take remedial action, if necessary. They may have to establish specific processes which determine the courses of action.

Successful businesses regularly analyse the customer service records. They gather data on the consumer sentiment toward products and brands as they continuously monitor the marketing environment (Cambria, 2016). They may collect data in real-time and use it well to personalise every aspect of their users' experience. Data-driven organisations strive to understand their customers' personas so that they target them with the right content with the relevant tone, imagery and value propositions. Usually they take advantage of the consumers' cognitive behaviour as they try to uncover and trigger consumer frailty at their individual level (Boucher Ferguson, 2013). It may appear that companies gather data on their customers in order to manipulate the market. They may use big data to delve into the enormous volumes of information that they collect during sales transactions in the day to day operations. The companies may use what they know about human psychology and consumer behaviour to set prices, draft contracts, minimise perceptions of danger or risk, or extract as much information as possible from their consumers (Boucher Ferguson, 2013).

In this day and age, marketing automation is helping businesses to engage with individuals whether they are customers or not. Behavioural targeting is nothing new in 
digital marketing. When firms hold detailed information about their consumers, they may customise every aspect of their interaction with them. Direct marketing tactics could prove the most effective way to reach consumers, when they are used wisely and diligently. Perhaps there could be scope for businesses to consider realigning their incentives with consumers by using data-driven marketing. Many businesses have learned to use databases as they gather valuable information to communicate and forge relationships with customers and prospects. This data collection may possibly drive new revenue streams and build long-term loyalty. Eventually, businesses could use this database to deliver promotional content to remind customers about their offerings. Their consumer lists whether they are automated or in the cloud should always be used to deliver enhanced customer experiences. Technology is instrumental for businesses in their ongoing interactions with people. Nevertheless, such marketing practices could possibly lead to unnecessary nuisances to the customer. Individuals are frequently bombarded with marketing endeavours including email promotions that are often picked up as spam. Therefore, one-size-fits-all messages could have negative implications on prospective customers.

Large technology conglomerates are increasingly using anonymous, cookieless data capture methods to gather the consumers' data as they track individual users' movements and measure traffic and other real-time phenomena (Fong et al., 2015). They may be using browsing session data combined with the consumers' purchase history to deliver "suitable" items that consumers like. As more consumers carry smartphones with them, they are (or shall be) receiving compelling offers that instantaneously pop up on their mobile devices. Recent advances in mobile communication and geo-positioning technologies have also presented marketers with a new way how to target consumers, based on their location. Location-targeted mobile advertising involves the provision of ad messages to cellular subscribers. This digital technology allows marketers to deliver ads and coupons that are customised to individual consumers' likings, geographic location and the time of day. Given the ubiquity of mobile devices, location-targeted mobile advertising seems to offer tremendous marketing benefits. The consumers who have social media apps on their 
smartphone are indicating their geo location as they move out and about. This same data can be used to identify where people gather. This information may be valuable to brands as they seek to improve their consumer engagement and marketing efforts. Yet, to date there has been little empirical evidence about the immediate and cumulative effectiveness of such mobile advertising.

EMarketer (2018) forecasted that mobile spending would account for about $82.5 \%$ of all US digital display ads. Notwithstanding, mobile marketers like Google or Facebook are benefiting from the smartphones' and tablets' geo-location capabilities. Large technology giants use geo-location capabilities to capitalise on these mobile technologies as they leverage location and context to obtain better information on shopping habits, lifestyle preferences and the like (Aksu et al., 2018). At the same time, the consumers are becoming increasingly acquainted with these marketing technologies. Therefore, they may decide to block advertisers and publishers from serving them ads. There may be customers who may be wary of giving their personal data due to privacy concerns. Recently, the New York Times and The Observer reported that a British consulting firm, Cambridge Analytica, had acquired and used the personal data of thousands of Facebook users who explicitly shared their data via a third-party app. As a result, Cambridge Analytica accessed their information and obtained data on the users' network. These Facebook users should have known very well what they were getting into. Out of their own volition, they consented to a third-party app using their personal data.

Very often, the advances in technology are faster than legislation and its deployment, as the use of digital data pushes the limits of the consumer protection law. In this light, the European Union (EU) Parliament has put forward its general data protection regulation (GDPR) that became effective as of 25 May 2018. In sum, the GDPR has replaced the Data Protection Directive 95/46/EC. The GDPR was designed to harmonise the data privacy laws across EU countries; to protect EU citizens from privacy and data breaches in an increasingly data-driven world (EU, 2018). The GDPR applies to all companies processing the personal data of online users (that are referred 
to as the subjects, residing in the EU). It transpires that the organisations that breach the EU's GDPR can be fined up to 4 per cent of annual global turnover or $€ 20$ million (whichever is greater). This is the maximum fine that can be imposed for the most serious infringements, like not having the customers' consent to process their data, or for violating the core of "Privacy by Design" concepts (EU, 2018). The conditions for consent have been strengthened, and companies will no longer be allowed to use long illegible terms and conditions, as the request for consent must be presented in an accessible form. Therefore, the online users' consent or withdrawal of consent must be in clear and plain language.

GDPR stipulates that the subjects have a right to obtain confirmation from the data holder as to whether or not their personal data is being processed, as organisations should explain where and for what purpose they are collecting the data. The data holders are expected to provide a copy of the personal data, free of charge, in an electronic format; if this data is requested by the subjects. Notwithstanding, the subjects can ask the data holders to erase their personal data, cease further dissemination of their data, and potentially third parties should not be allowed to process this data. Therefore, the gathered data will no longer remain relevant for its original purposes without the subjects' consent.

\section{Analysing data}

Organisations can use the consented data that was provided to them by the online users. However, they may avail themselves of other data sources from the macro environment, including competitive activities, marketing actions, customer service records, etc. They may use analytics to create a good picture of their marketing performance, as they can provide them with insights for their customer-centric strategies (Nichols, 2013). Companies can use data for many purposes. They could quantify the contribution of each element of advertising; run scenarios for business planning; and allocate resources in real-time across marketing activities. In real-time monitoring contexts, organisations need to adopt a more continuous approach to analysis and decision making, that are based on a series of hunches and hypotheses (Davenport, 2014; Davenport et al., 2012). 
The analytics software could provide detailed information on sales data and advertising metrics, by medium and location. A data analysis of one campaign may reveal that the marketing communications may work independently of one another (Nichols, 2013). The latest analytics packages can reveal the impact of marketing activities in different media. This happens because the consumer behaviours might change in response to advertising stimuli. For instance, an analysis could pick up a spike in consumers clicking through online banner ads, after they have watched a TV ad, social media placement or in-store promotion (Kumar et al., 2017). Therefore, analytics can reveal the "assist effects" of the traditional marketing communications on digital media (Cheng and Edwards, 2015; Nichols, 2013).

Once the marketers have quantified the relative contribution of each marketing communications channel, they may use predictive-analytical tools to run scenarios for business planning (Siegel, 2016). These analytics will reveal the implications of increasing or decreasing marketing expenditures to optimise the marketing mix, and to guide spending allocation on particular media. The statistical models could reveal that the effect of advertising on consumer behaviour may be related to market conditions, marketing actions and competitive activities. Data on the consumers' response to the marketing communications must be fed into the analytics system to fine-tune the corporate spending through different media. Such optimisation software can generate realistic contexts along with relevant marketing recommendations to achieve them. For example, the analytics software can test specific what-if scenarios, measure outcomes, validate models and make corrections before making decisions (Siegel, 2016). Today's marketers can readily adjust or reallocate online advertising budgets in different markets in a fraction of a second (Nichols, 2013). Analytics will help them understand which marketing activities are driving leads to websites, and intermediaries.

Today, companies can quantify the precise combination of ads that will be the most effective (Kumar et al., 2017; Nichols, 2013). They can identify how advertising of one product category influences the purchasing of others. Therefore, firms can benefit from 
such information, as they make fact-based decision making when they allocate adequate and significant resources for their advertising and promotions. They can also monetise data by increasing revenue whilst reducing expenses. In addition, data may be used to improve the speed to market and to enhance customer service levels (Watson, 2017; Woerner and Wixom, 2015).

Some firms have experienced optimal results after they have integrated analytics within their core businesses' operational and production tasks (Abbasi et al., 2016; Loebbecke and Picot, 2015). However, this proves a difficult task for many organisations, as they are increasingly dealing with massive volumes of data, analytics, algorithms and user interfaces. Many businesses are increasingly recognising the value of building a datadriven organisational culture (Hartmann et al., 2016). The greatest barrier to achieving this is the individuals' attitudes toward technology and change (Andrejevic, 2014; Russell Neuman et al., 2014). Therefore, organisations should train and recruit competent individuals with new digital literacies. Recently, there has been an ongoing requirement for skilled professionals in this promising area of study. They may often possess advanced degrees in computer science, management information systems or network-oriented social sciences (Davenport et al., 2012; Horlacher and Hess, 2016). Highly qualified individuals are expected to support the tourism businesses' data and information management. In some service sectors, data scientists have become an integral part of the research and development team (Horlacher and Hess, 2016).

In the past, the marketing information systems function involved monitoring, controlling processes and notifying management about anomalies. The most vaunted business and IT capabilities used to be stability and scale (Davenport et al., 2012). Today, the analysis of data can be categorised as descriptive, predictive analytics and prescriptive analytics (Deka, 2016; Halavais, 2015; Ransbotham et al., 2015). Descriptive analytics focuses on what happened in the past and why. Predictive analytics uses models to forecast the future (Fu et al., 2018), as they could quantify the likelihood that a particular person will do something - whether it is defaulting on a loan, upgrading to a higher level of cable service or seeking another job (Siegel and 
Davenport, 2013). It may appear that predictive analytics anticipates human behaviours that have not happened yet (Fu et al., 2018). For instance, predictive tools and smart cards enabled Singapore Land Transit Authority to provide a more convenient transportation system to commuters and leisure passengers. Siegel and Davenport (2013) explained how quantitative techniques can be deployed to find valuable patterns in data that can enable companies to predict the likely behaviour of customers, employees and others. They distinguished between forecasting and predictive analytics. They maintained that forecasting could estimate future sales, whereas predictive data will provide additional details of customer personas, segments and prospects. Siegel and Davenport (2013) referred to the "Prediction Effect" as they suggested that minor increases in the data accuracy of predictions can often lead to substantial savings in the long term.

Prescriptive analytics anticipates what will happen, when it will happen and explains why it will happen (Deka, 2016). Therefore, it prescribes better decision options. Although individuals tend to regularly repeat their habitual behaviours, predictive analytics cannot determine when and why they may decide to change their future preferences. Yet, the possibility of "one-off" events must never be discounted (Gandomi and Haider, 2015).

\section{Distributing data}

The use of advanced analytics has led to the development of a programmatic advertising (or real-time advertising) in the digital media; where buyers and sellers of online advertising connect to exchange available inventory (Busch, 2016; Rayport, 2015; Stevens et al., 2016). The programmatic advertising environment offers remarkable speeds and sophistication levels, as online users click on URLs. In a short period (less than a second), an algorithm evaluates an optimal bid for an advertiser, and a real-time auction determines the winning bid (Jerath and Savary, 2017). As a result, the winning ad is displayed, and the advertiser is notified that the ad had been viewed by online prospects. The analytics technology has enabled the technology giants to deliver targeting and re-targeting solutions with instantaneous pricing and access, across digital 
channels (including mobile, video, social, etc.) (Rayport, 2015). Therefore, programmatic advertising is set to continue captivating the cross-media creative and media industry over the coming years, as it forms the basis of distributive advertising and marketing on every level (Busch, 2016).

Another disruptive innovation is blockchain's distributed ledger technology. In the past, companies could have struggled to determine the value of their business, including patents, trade secrets and other intellectual property. However, the emerging blockchain technologies are helping to create marketplaces for data, whilst improving data privacy (FEDS, 2016). Blockchain is a new platform technology enabling an improved ability to verify and record the exchange of value among an interconnected set of users; it is a secure and transparent way to track the ownership of assets before, during and after any transaction (Lakhani, 2017). Hence, this technology meets the user's confidentiality and consistency requirements. As a result, organisations share their data in a safe environment, because there's more protection in terms of cryptography and protocols. Blockchain has stringent requirements for privacy and confidentiality, but also for auditability (FEDS, 2016). The regulatory authorities may need to know who was behind a certain transaction, particularly in the service industries.

Blockchain records a history of all transactions within it, and all users in the network have an identical copy of the record/ledger. The network using the blockchain agrees on and governs the rules for its use. It protects all data and information, and the use of digital keys and digital signatures is required to access data in the ledger (Lakhani, 2017). The blockchain's data is permanent and the details of all recorded transactions cannot be altered retroactively without the full agreement of the network.

Moreover, the blockchain's ledger reflects any changes in real time, and the records of all transactions can be maintained and updated securely by the users themselves. These benefits enable the development of many potential products and applications for industry. Current blockchain products and applications, include: (i) the clearing, payments and settlement functions in financial services companies, (ii) creation and use 
of a digital identity within an enterprise and (iii) smart contracts (Iansiti and Lakhani, 2017; Kosba et al., 2016). Blockchain can facilitate cross-borders payments among marketplace stakeholders, including suppliers, intermediaries and consumers. Very often, the tourism businesses' payment options are highly intermediated, costly and time consuming. Additionally, the online transactions would be secure, private and verifiable (Iansiti and Lakhani, 2017). This technology could potentially drive cost savings that could lead to lower costs being passed to the consumers of the tourism industry.

\section{Discussion and conclusion}

The latest disruptive technologies are supporting the tourism businesses' marketing mix elements as they improve the interactive engagement with individual prospects, and enhance the personalisation of services, whilst providing secure pricing options. Many tourism firms are evolving from their passive, rigid and product-centric state to a more flexible, dynamic and customer-centric environment, as they monitor and detect any changes in consumer sentiment. Data-driven companies are increasingly capturing and analysing the online and mobile activity of prospective customers, as they delve into ecommerce and review sites, personal blogs and social media (Kumar et al., 2017; Sigala, 2017). Their analytics captures the consumers' interactions with brands and companies through digital media. Therefore, big data is enabling them to target and re-target individuals and online communities with instantaneous pricing and access options, across multiple channels (via website activity, mobile, video, social media, ecommerce, among others) (Camilleri, 2015). Large technology giants use mobile tracking technologies, to gather information on the consumer behaviours, including their shopping habits, lifestyle preferences, etc. (Aksu et al., 2018).

Tech-savvy firms have learnt how to take advantage of on-demand, real-time information from sensors, radio frequency identification and other location tracking devices to better understand their marketing environments at a more granular level (Storey and Song, 2017). This way business could come up with personalised products and services, that are demanded by individual customers (Li et al., 2017). From a 
business perspective, it is important to acquire this data, quickly, and in high velocities. This chapter reported that many businesses are already benefiting of the programmatic advertising environment; where buyers and sellers of digital advertising connect online to exchange available inventory (Busch, 2016; Stevens et al., 2016).

The challenge for tourism businesses is to recognise the value of smart technologies as effective tools that can analyse their marketing environment, including the customers as well as their competitors. The predictive-analytical tools can examine different scenarios; and the prescriptive analytics anticipate what will happen, when it will happen and explains why it happens. These technologies can monetise data by identifying revenue generating opportunities and cost savings.

Other innovations, including blockchain's distributed ledger technologies are improving data privacy, as it involves the verification and the secure recording of transactions among an interconnected set of users. Blockchain tracks the ownership of assets before, during and after any online transaction. Therefore, this technology could be used by tourism businesses to facilitate their transactions with marketplace stakeholders, including suppliers, intermediaries and consumers across borders. The blockchain will probably be more convenient than other payment options, in terms of time and money. Therefore, blockchain's ledger technology can possibly lead to better customer service levels and operational efficiencies for the tourism businesses.

The smart tourism technologies, including big data analytics, are shifting how organisations collect, analyse and utilise and distribute data. A thorough literature review suggests that the crunching of big data analytics is generating meaningful insights and supporting tourism marketers in their decision making. Moreover, other technologies, including the programmatic advertising and blockchain are helping them to improve their financial and strategic performance, whilst minimising costs. In conclusion, this contribution calls for further research on data-driven tourism. Table 11.1 illustrates how smart tourism businesses are capturing, analysing and distributing data. 
Table 11.1 The Data Processing Cycle

\begin{tabular}{|c|c|}
\hline Capturing Data & $\begin{array}{l}\text { Online and mobile users' behaviour in } \\
\text { real-time } \\
\text { Customer service records } \\
\text { Referral sources and product } \\
\text { recommender systems } \\
\text { Consumers' personal preferences } \\
\text { Website activity } \\
\text { Social media networks } \\
\text { Ecommerce platforms } \\
\text { Comprehensive information in a } \\
\text { database }\end{array}$ \\
\hline Analysing Data & $\begin{array}{l}\text { Descriptive analytics } \\
\text { Predictive analytics } \\
\text { Prescriptive analytics }\end{array}$ \\
\hline Distributing Data & $\begin{array}{l}\text { Programmatic advertising } \\
\text { Blockchain distributed ledger technology }\end{array}$ \\
\hline
\end{tabular}

(Camilleri, 2019)

\section{Emerging trends and future research}

Tomorrow's tourism businesses will be serving customers from geographically diverse regions. There will be more travellers from emerging markets and developing economies. The tourism service providers will have to cater to different demographics, including senior citizens and individuals with special needs; as there are ageing populations in many countries. Therefore, smart technologies can be used to anticipate the discerned consumers' requirements. For instance, the use of programmatic advertising will probably increase the individuals' intuitive shopping experiences and can tap into the travellers' discretionary purchases. It is very likely that the third-party retailers will continue to form part of the distribution mix. However, many service providers will be using their direct channels to reach out to their targeted customers. 
The multinational technology companies, including Google, Facebook, Amazon and IBM could be playing a much larger role in travel distribution. In fact, Google is already disrupting the tourism industry as its travel product, Google Flights, is increasing in popularity among travellers.

The sales of the tourism products will continue to rely on mobile devices with increased consumer interactions through speech and voice recognition software. The tourism service providers may possibly rely on artificial intelligence and other forms of cognitive learning capabilities, like machine learning and deep learning. The travel industry's distributive systems could interface with virtual reality software to help online intermediaries to merchandise their products in captivating customer experiences. Notwithstanding, many online prospects may use blockchain's secure technology to purchase tourism products, in the foreseeable future.

Therefore, this contribution calls for further empirical research that could explore smart tourism innovations for individuals and organisations, including mobile social networking, mobile visualisation, personalisation and behavioural modelling for mobile apps, programmatic advertising, blockchain, AI and the Internet of Things, among other areas.

\section{References}

Abbasi, A., Sarker, S. and Chiang, R. H. (2016), "Big data research in information systems: Toward an inclusive research agenda", Journal of the Association for Information Systems, Vol. 17 No. 2, pp. 1-32.

Aksu, H., Babun, L., Conti, M., Tolomei, G., and Uluagac, A. S. (2018), "Advertising in the IoT Era: Vision and challenges". IEEE Communications Magazine.

Andrejevic, M. (2014), "Big data, big questions: The big data divide", International Journal of Communication, Vol. 8, pp. 1673-1689.

Boucher Ferguson, R. (2013), "Is digital advertising a new form of market manipulation?", MIT Sloan Review. Available at: http://sloanreview.mit.edu/article/is-digital-advertising-anew-form-of-market-manipulation/ (Accessed 20th May, 2018).

Boyd, D., and Crawford, K. (2012), "Critical questions for big data: Information", Communication and Society, Vol. 15 No. 5, pp. 662-679. 
Buhalis, D., and Amaranggana, A. (2013), "Smart tourism destinations". In Z. Xiang and I. Tussyadiah (eds), Information and Communication Technologies in Tourism 2014 (pp. 553564). Springer, Cham, Switzerland.

Busch, O. (2016), “The programmatic advertising principle”, in O. Busch (ed.), Programmatic Advertising (pp. 3-15). Springer, Cham, Switzerland.

Cambria, E. (2016), "Affective computing and sentiment analysis", IEEE Intelligent Systems, Vol. 31 No. 2, pp. 102-107.

Camilleri, M.A. (2015). Using Big Data for Customer-Centric Marketing. In Evans, C. (Ed) Handbook of Research on Open Data Innovations in Business and Government, IGI Global, Hershey, USA. https://www.um.edu.mt/library/oar/handle/123456789/10682

Camilleri, M.A. (2017). Travel Marketing, Tourism Economics and the Airline Product: An Introduction to Theory and Practice. Springer, Cham, Switzerland. ISBN 978-3-319-498492 http://www.springer.com/us/book/9783319498485\#aboutBook

Camilleri, M.A. (Ed.) (2018). Tourism Planning and Destination Marketing. Emerald, Bingley, UK. ISBN: $\quad$ 978-1-78756-292-9 https://books.emeraldinsight.com/page/detail/The-Branding-ofTourist-Destinations/?K=9781787693746

Chen, C. P., and Zhang, C. Y. (2014), "Data-intensive applications, challenges, techniques and technologies: A survey on Big Data”, Information Sciences, Vol. 275, pp. 314-347.

Chen, H., Chiang, R. H. and Storey, V. C. (2012), "Business intelligence and analytics: From big data to big impact", MIS Quarterly, Vol. 36 No. 4, pp. 1165-1188.

Cheng, M., and Edwards, D. (2015), "Social media in tourism: A visual analytic approach", Current Issues in Tourism, Vol. 18 No. 11, pp. 1080-1087.

Davenport, T. (2014), "How strategists use 'big data' to support internal business decisions, discovery and production”, Strategy and Leadership, Vol. 42 No. 4, pp. 45-50.

Davenport, T. H., Barth, P. and Bean, R. (2012), "How 'big data' is different". MIT Sloan Management Review. Available at: https://sloanreview.mit.edu/article/how-big-data-isdifferent/ (Accessed May 15th, 2018).

Deka, G. C. (2016), "Big data predictive and prescriptive analytics". In Big Data: Concepts, Methodologies, Tools, and Applications (pp. 30-55). IGI Global, Hershey, USA.

EMarketer (2018), "More than $80 \%$ of digital display ads will be bought programmatically in 2018". Available at: www.emarketer.com/content/more-than-80-of-digital-display-ads-willbe-bought-programmatically-in-2018 (Accessed 23rd May, 2018).

EU (2018), "2018 reform of EU data protection rules”, EU commission, Brussels, Belgium. Available at: https://ec.europa.eu/commission/priorities/justice-and-fundamental-rights/dataprotection/2018-reform-eu-data-protection-rules_en (Accessed 2nd May, 2018).

FEDS (2016), "Distributed ledger technology in payments, clearing, and settlement", Finance and Economics Discussion Series Divisions of Research and Statistics and Monetary Affairs. 
Federal Reserve Board, Washington, DC. Available at: www.federalreserve.gov/econresdata/feds/2016/files/2016095pap.pdf (Accessed 14th May, 2018).

Fong, N. M., Fang, Z., and Luo, X. (2015), "Geo-conquesting: Competitive locational targeting of mobile promotions", Journal of Marketing Research, Vol. 52 No. 5, pp. 726-735.

Fu, Y., Hao, J. X., Li, X. and Hsu, C. H. (2018), "Predictive accuracy of sentiment analytics for tourism: A metalearning perspective on Chinese travel news", Journal of Travel Research. Available at: http://journals.sagepub.com/doi/abs/10.1177/0047287518772361 (Accessed 25th May, 2018).

Gandomi, A., and Haider, M. (2015), "Beyond the hype: Big data concepts, methods, and analytics", International Journal of Information Management, Vol. 35 No. 2, pp. 137-144.

Gao, S., Tang, O., Wang, H. and Yin, P. (2018), "Identifying competitors through comparative relation mining of online reviews in the restaurant industry", International Journal of Hospitality Management, Vol. 71, pp. 19-32.

Gretzel, U., Sigala, M., Xiang, Z. and Koo, C. (2015), "Smart tourism: Foundations and developments", Electronic Markets, Vol. 25 No. 3, pp. 179-188.

Halavais, A. (2015), "Bigger sociological imaginations: Framing big social data theory and methods", Information, Communication and Society, Vol. 18 No. 5, pp. 583-594.

Hartmann, P. M., Zaki, M., Feldmann, N. and Neely, A. (2016), "Capturing value from big data - a taxonomy of data-driven business models used by start-up firms", International Journal of Operations and Production Management, Vol. 36 No. 10, pp. 1382-1406.

Horlacher, A., and Hess, T. (2016), "What does a Chief Digital Officer do? Managerial tasks and roles of a new C-level position in the context of digital transformation", In System Sciences (HICSS), 2016 49th Hawaii International Conference (pp. 5126-5135). IEEE.

Iansiti, M., and Lakhani, K. R. (2017), "The truth about blockchain", Harvard Business Review, Vol. 95 No. 1, pp. 118-127.

Jerath, K., and Savary, M. (2017), "A primer on programmatic advertising", Columbia University, NY, USA.

Kosba, A., Miller, A., Shi, E., Wen, Z. and Papamanthou, C. (2016), "The blockchain model of cryptography and privacy-preserving smart contracts", in Security and Privacy (SP), 2016 IEEE Symposium (pp. 839-858). IEEE.

Kumar, V., Choi, J. B., and Greene, M. (2017), "Synergistic effects of social media and traditional marketing on brand sales: Capturing the time-varying effects", Journal of the Academy of Marketing Science, Vol. 45 No. 2, pp. 268-288.

Lakhani, K. (2017), "Blockchain - what you need to know". Available at: https://hbr.org/ideacast/2017/06/blockchain-what-you-need-to-know (Accessed 28th April, 2018). 
Li, Y., Hu, C., Huang, C., and Duan, L. (2017), "The concept of smart tourism in the context of tourism information services", Tourism Management, Vol. 58, pp. 293-300.

Liu, Y., Teichert, T., Rossi, M., Li, H., and Hu, F. (2017), "Big data for big insights: Investigating language-specific drivers of hotel satisfaction with 412,784 user-generated reviews", Tourism Management, Vol. 59, pp. 554-563.

Loebbecke, C., and Picot, A. (2015), "Reflections on societal and business model transformation arising from digitization and big data analytics: A research agenda", The Journal of Strategic Information Systems, Vol. 24 No. 3, pp. 149-157.

Nichols, W. (2013), “Advertising Analytics 2.0”, Harvard Business Review. https://hbr.org/2013/03/advertising-analytics-20 (Accessed 20th May, 2018).

Pan, B., and Yang, Y. (2017), "Forecasting destination weekly hotel occupancy with big data", Journal of Travel Research, Vol. 56 No. 7, pp. 957-970.

Ransbotham, S., and Kiron, D. (2018), "Using analytics to improve customer engagement", MIT Sloan Management Review. Available at: https://sloanreview.mit.edu/projects/usinganalytics-to-improve-customer-engagement/ (Accessed 21st May, 2018).

Ransbotham, S., Kiron, D. and Prentice, P. K. (2015), "Minding the analytics gap", MIT Sloan Management Review, Vol. 56 No. 3, pp. 63-68.

Ratten, V. (2020). Cloud computing technology innovation advances: a set of research propositions. In Disruptive Technology: Concepts, Methodologies, Tools, and Applications (pp. 693-703). IGI Global.

Rayport, J. F. (2015), "Is programmatic advertising the future of marketing?", Harvard Business Review. Available at: https://hbr.org/2015/06/is-programmatic-advertising-thefuture-of-marketing (Accessed 23rd May, 2018).

Russell Neuman, W., Guggenheim, L., Mo Jang, S. and Bae, S. Y. (2014), "The dynamics of public attention: Agenda-setting theory meets big data", Journal of Communication, Vol. 64 No. 2, pp. 193-214.

Siegel, E. (2016), Predictive Analytics: The Power to Predict Who Will Click, Buy, Lie, or Die, John Wiley and Sons. New York, USA.

Siegel, E., and Davenport, T. H. (2013), Predictive Analytics: The Power to Predict Who Will Click, Buy, Lie, or Die, Wiley, New York, USA.

Sigala, M. (2017), "Collaborative commerce in tourism: Implications for research and industry”, Current Issues in Tourism, Vol. 20 No. 4, pp. 346-355.

Stergiou, C., Psannis, K. E., Kim, B. G. and Gupta, B. (2018), "Secure integration of IoT and cloud computing”, Future Generation Computer Systems, Vol. 78, pp. 964-975. 
Stevens, A., Rau, A. and McIntyre, M. (2016), "Integrated campaign planning in a programmatic world", in O. Busch (ed.), Programmatic Advertising (pp. 193-210), Springer, Cham, Switzerland.

Storey, V. C., and Song, I. Y. (2017), "Big data technologies and management: What conceptual modeling can do?", Data and Knowledge Engineering, Vol. 108, pp. 50-67.

Wang, Y., Kung, L. and Byrd, T. A. (2018), "Big data analytics: Understanding its capabilities and potential benefits for healthcare organizations", Technological Forecasting and Social Change, Vol. 126, pp. 3-13.

Watson, H. (2017), "The cognitive decision-support generation", Business Intelligence Journal, Vol. 22 No. 2, pp. 5-14.

Woerner, S. L., and Wixom, B. H. (2015), "Big data: Extending the business strategy toolbox", Journal of Information Technology, Vol. 30 No. 1, pp. 60-62.

Xiang, Z., Du, Q., Ma, Y. and Fan, W. (2017), “A comparative analysis of major online review platforms: Implications for social media analytics in hospitality and tourism", Tourism Management, Vol. 58, pp. 51-65. 